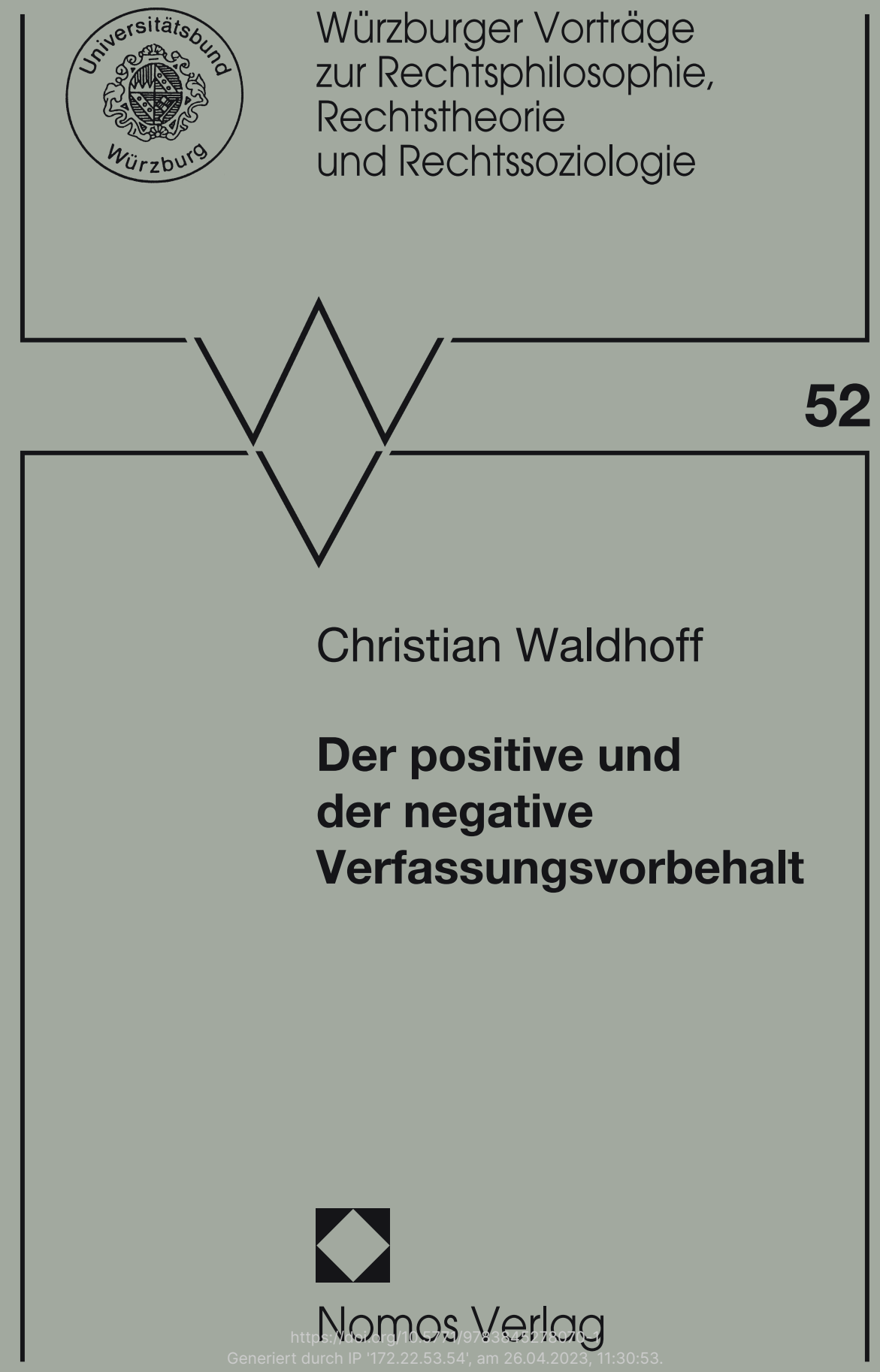


Würzburger Vorträge zur Rechtsphilosophie, Rechtstheorie und Rechtssoziologie

Herausgegeben von Horst Dreier und Dietmar Willoweit

Begründet von Hasso Hofmann, Ulrich Weber ${ }^{\dagger}$ und Edgar Michael Wenz ${ }^{\dagger}$

Heft 52 
Christian Waldhoff

\section{Der positive und der negative Verfassungsvorbehalt}

Überlegungen zu einer Regelungstheorie im Grenzbereich von Verfassungsrechtsdogmatik und Verfassungstheorie 
Vortrag gehalten am 14. Januar 2016

Die Deutsche Nationalbibliothek verzeichnet diese Publikation in der Deutschen Nationalbibliografie; detaillierte bibliografische Daten sind im Internet über http://dnb.d-nb.de abrufbar.

ISBN 978-3-8487-3504-4 (Print)

ISBN 978-3-8452-7807-0 (ePDF)

1. Auflage 2016

(c) Nomos Verlagsgesellschaft, Baden-Baden 2016. Gedruckt in Deutschland. Alle Rechte, auch die des Nachdrucks von Auszügen, der fotomechanischen Wiedergabe und der Übersetzung, vorbehalten. Gedruckt auf alterungsbeständigem Papier. 


\section{Inhaltsverzeichnis}

I. Einleitung 7

II. Der Verfassungsvorbehalt - Begriff und Bedeutungsfelder 13

1. Die verhängnisvolle Begriffsähnlichkeit zum Gesetzmäßigkeitsprinzip

2. „Positiver“ und „,negativer“ Verfassungsvorbehalt: Was muss/sollte in die Verfassung, was darf nicht/sollte nicht in die Verfassung aufgenommen werden?

3. Beispiele ausdrücklicher und partieller Verfassungsvorbehalte unter dem Grundgesetz

4. Originärer und abgeleiteter Verfassungsvorbehalt: Verfassungsinhalte zwischen Verfassunggebung und Verfassungsänderung

5. Begrenzter Befund in der Judikatur des Bundesverfassungsgerichts

III. Der verfassungsrechtsdogmatische normative Verfassungsvorbehalt als Funktion des Vorrangs der Verfassung

1. Der Vorrang der Verfassung 27

2. Die Frage nach dem Eigenstand eines Vorbehalts neben dem Vorrang der Verfassung als Frage nach einer normhierarchisch hochgezonten Wesentlichkeitstheorie

a) Der Vorbehalt der verfassungsmäßigen Rechtserzeugung

b) Als Gegenprobe: Vorrang und Vorbehalt der Verfassung in der englischen Verfassung

3. Anwendungsfelder

a) Der Verfassung vorgelagerte Fragen - Numerus clausus der Rechtsetzungsformen? 
b) Staatsorganisationsrecht: Einfachgesetzliche Einführung direktdemokratischer Elemente in das Grundgesetz?

c) Inhaltliche Verfassungsvorbehalte - Die

Staatsaufgabendiskussion

aa) Staatsaufgaben als Produkt des politischen Prozesses

bb) Als Gegenmodell: Explizite

Staatsaufgabenvorbehalte

IV. Der verfassungstheoretische Verfassungsvorbehalt als Theorie des Verfassungsinhalts

1. Diachrone und synchrone Typologie: Was gelangt(e) wann und warum in Verfassungstexte?

2. Die Kontingenz von Idealbildern der Verfassung: Vom universalistischen Anspruch zur kontextualisierten Verfassungsfunktionenlehre

3. "Verfassungswürdigkeit" und

„Verfassungsunwürdigkeit" von Verfassungsinhalten als

Probleme einer Gesetzgebungslehre der Verfassung?

4. Die Problematik des negativen Verfassungsvorbehalts

a) Verweisungen und Öffnungen des Verfassungstextes als explizite negative Verfassungsvorbehalte?

b) Die Problematik der normhierarchischen Hochzonung inhaltlicher Festlegungen - von der etatistischen zur demokratietheoretischen Argumentation

5. Die Bedeutung der Verfassungsgerichtsbarkeit für die Frage des Verfassungsvorbehalts - Vom Vorbehalt zur Bestimmtheit der Verfassung?

6. Einflüsse der Inter- und Supranationalisierung auf notwendige Verfassungsinhalte

V. Schluss: Verfassungsinhalt und Verfassungsfunktion 